\title{
Synthesis and Physicochemical Characteristics of Chitosan Extracted from Pinna deltoides
}

\author{
Rahul Varma ${ }^{1(D)}$, Sugumar Vasudevan ${ }^{1, *(D)}$, Stella Chelladurai ${ }^{1}$ (D), Anandhan Narayanasamy ${ }^{2(D)}$ \\ 1 Department of Oceanography and Coastal Area Studies, Alagappa University, Karaikudi, 630003, Tamilnadu, India \\ 2 Department of Physics, Alagappa University, Karaikudi, 630003, Tamilnadu, India \\ * Correspondence: crustacealab@gmail.com (S.V.);
}

Scopus Author ID 14062419600

Received: 9.07.2021; Revised: 22.08.2021; Accepted: 26.08.2021; Published: 30.10.2021

\begin{abstract}
Chitosan, a naturally produced polysaccharide that has a wide range of uses in biological, pharmacological, industrial, and commercial settings. The pen shell Pinna deltoides is a common species found along the coast of Thondi, and it is often collected as by-catch by fishermen. These species contain a high amount of chitin, which may be converted into chitosan. The goal of this research is to extract chitosan from $P$. deltoides and characterize it utilizing techniques like Fourier Transform Infrared Spectroscopy (FTIR), Micro Raman Spectroscopy, X-ray Powder Diffractometry (XRD), Thermogravimetric Analysis (TGA), and Scanning Electron Microscopy (SEM). The existence of CO-C glycosidic connection (1156 $\left.\mathrm{cm}^{-1}\right)$, NHCO group $\left(1216 \mathrm{~cm}^{-1}\right)$, aliphatic compound, $-\mathrm{CH}_{2}$ bend $\left(1418 \mathrm{~cm}^{-1}\right)$, and asymmetric $\mathrm{CH}_{2}$ stretching were verified by FTIR analysis $\left(1204 \mathrm{~cm}^{-1}\right)$. Chitosan extract exhibited a greater degree of deacetylation of $55.17 \%$, which is consistent with prior studies. The highest peaks in the Micro Raman Spectra were $2937 \mathrm{~cm}^{-1}, 1106 \mathrm{~cm}^{-1}$, and $1376 \mathrm{~cm}^{-1}$. The crystallinity of the chitosan at $2 \theta$ was anticipated using X-ray Powder Diffractometry (XRD) data at about $20^{\circ}-25^{\circ}$. SEM micrograms verified the crystalline nature of the chitosan by revealing its soft and crystal-like arrangement of the chitosan. TGA was used to assess the sample's thermal constancy, and the chitosan's stability was found to be consistent with that of prior research.
\end{abstract}

Keywords: chitosan; characterization; biopolymer, Pinna shells.

(C) 2021 by the authors. This article is an open-access article distributed under the terms and conditions of the Creative Commons Attribution (CC BY) license (https://creativecommons.org/licenses/by/4.0/).

\section{Introduction}

Chitin is an undisruptive, degradable polymer with a high molecular weight that occurs naturally. Chitin is a chief constituent of invertebrates and crustaceans [1,2]. Chitin is a linear biopolymer poised of $(1,4)$ glycosidic bond units connected by 2-acetamide-2-deoxy-Dglucopyranose. According to the previous literature, chitin varies from cellulose mostly because of the manifestation of acetamide groups at $\mathrm{C}-\mathrm{Z}$ spots. The two allomorphs of $\alpha$ chitin and $\beta$ chitin are highly reliant on the chitin source. Alpha Chitin is abundant in the shells of crustaceans [3,4]. The remarkable properties of chitin and its derivatives result in immunostimulant, decoagulant, enzyme repressive, germicidal, antitumor, anti-cholesteremic and laceration curative capabilities. These chitin and chitosan particles have also been used as biosorbent, allowing them to filter metal ions out of polluted water [5].

The deacetylation technique is the most widely used method for chitosan extraction. Chitosan is a polysaccharide containing N-acetyl-D-glucosamine and (1-4)-linked Dglucosamine units in unpredictably large amounts [6]. Chitosan was discovered in the 18th 
century, but it wasn't until the 1970s that its actual value was realized [7]. Chitosan biopolymers have an eclectic series of utilizations, especially in the domain of medical appliances. Chitosan has a variety of properties since it is extremely biocompatible and environmentally friendly [8]. The occurrence of primary amine at the C-2 point of glucosamine deposits gives chitosan its distinct structural characteristics. Chitosan's varied functions are because of the incidence of an amine at the C-2 site [9,10]. The degree of deacetylation as well as the molecular weight of chitosan is having a big impact on physicochemical and mechanical characteristics of chitosan particles. The level of deacetylation of chitosan is correspondingly used to gauge other properties of the chitosan, such as hydrophobicity, solubility, and toxicity [9,11].

The typical peaks ascribed to polysaccharide structures may be seen in the FTIR of chitosan [12]. The spectrum obtained also demonstrates efficient deacetylation, which occurs when acetamido $\left(\mathrm{CH}_{3} \mathrm{CONH}\right)$ groups are removed, and additional amine $\left(\mathrm{NH}_{2}\right)$ groups are formed [13]. The occurrence of hydroxyl group, amine, carboxylic, and alkyl assemblages and amide associations may all be seen in the FTIR spectrum [14]. The success of the quaternization of N-alkyl chitosan may be determined by Attenuated Total Reflectance-Fourier Transform Infrared Spectroscopy (ATR-FTIR) $[15,16]$. The Raman spectra were used to determine the six-membered loop encompassing $\mathrm{O}_{2}$ along with the different peaks belonging to chitosan, and the inelastic diffusing of photons is important to this technique [17-19].

The chitosan X-ray powder diffraction (XRD) displays broad reflections in $2 \theta$ at $19.82^{\circ}-20.45^{\circ}$ [20]. Chitosan has a crystallinity degree of $80 \%$, according to previous research [21,22]. Experiments using XRD have revealed that chitosan samples had sharper bands than its counterpart, with a trivial deterioration in crystalline percentage [4]. The instrumentations such as the Thermogravimetric Analysis (TGA), Dynamical Mechanical Thermal Analysis (DMTA) as well as the Differential Scanning Calorimetry (DSC) have all been established to be helpful diagnostic methods for tracking the physical and chemical changes that occur during chitosan heating as well as evaluating chemical structure and composition [23]. According to earlier research, the Thermogravimetric Analysis (TGA) of chitosan revealed that mass loss occurs in three stages: water evaporation, chitosan loss and chitin loss, respectively [24]. According to certain research, chitosan's thermal stability is directly related to its crystalline nature, meaning that the thermal stability of chitosan rises as the crystallinity of chitosan increases [25].

The Pinnidae family of bivalves consists of the huge wedge-molded bivalves that dwell in the mire, amid rocks and corals, and sand. The Pinnidae family of shells is known by several names, including pen, razor, fan, and wing shells. A mass of long byssus threads holds the submerged anterior end of the shell in place, while the flared posterior edge protrudes from the ground. The Pinnidae family may be found in both tropical and temperate waters across the world. The Indo-Pacific genus Pinna deltoides may be found from eastern Africa to Lord Howe Island and Pakistan, as well as in the southern parts of India as well as in the Indo-Malay Archipelago. Pinna deltoides habitat data is mostly collected from rough substrata such as flats and rock-strewn reefs as well as heads and coral blocks [26]. These Pinnidae species' shells were chosen for the study because they are frequently abandoned as waste materials and may be found on the shoreline, where they lay unused. These samples were chosen for chitosan conversion to generate value-added goods. To extract chitosan from Pinna deltoides and analyse the isolated chitosan, researchers employed FTIR, Micro Raman spectroscopy, XRD, TGA and SEM. 


\section{Materials and Methods}

Decolourization, demineralization, and deproteinization are the three key phases in the chitin extraction process [27]. For the decolorization procedure, the raw materials obtained from Pinna deltoides were mixed for 10 minutes at $100^{\circ} \mathrm{C}$ with 10 milliliters of sodium hypochlorite emulsion. To produce discoloration, this procedure is performed several times. For the demineralization process, the sample was combined with $20 \mathrm{ml}$ of 1 molar hydrochloric acid at $70^{\circ} \mathrm{C}$ for 15 minutes. The sample was deproteinized by inserting 20 milliliters of 1 molar sodium hydroxide $(\mathrm{NaOH})$ into the solution and refluxing it for 20 minutes at $100^{\circ} \mathrm{C}$. The sample was carefully washed down with filtered water to extract chitin until the $\mathrm{pH}$ stood low to the range of 6.5-7.5, then dried at room temperature. The chitin produced was allowed to react at $110^{\circ} \mathrm{C}$ for 24 hours with $15 \mathrm{ml}$ of $45 \% \mathrm{NaOH}$ [28]. The resultant material was rinsed in sterile water before being $\mathrm{pH}$ stabilized and strained to eliminate chitosan.

\subsection{Characterization of chitosan.}

\subsubsection{Fourier Transform Infrared Spectroscopy (FTIR).}

Using the Perkins-Elmer spectrometer (Spectrum RX I, MA, USA), the resulting chitosan sample was laid open to FTIR by carefully mixing with $\mathrm{KBr}$. The infrared spectra of $\mathrm{KBr}$ reinforced chitosan were gaged at a resolution of $4 \mathrm{~cm}^{-1}$ throughout the frequency scaled between $4000-400 \mathrm{~cm}^{-1}$.

The degree of acetylation (DA) was determined in triplicate using FTIR [28].

$$
\mathrm{DA}(\%)=\left(\mathrm{A}_{1653} / \mathrm{A}_{3445}\right) * 115
$$

where $A_{1653}$ represents the absorption degree at $1653 \mathrm{~cm}^{-1}$ and $A_{3445}$ denotes the absorption degree at $3445 \mathrm{~cm}^{-1}$.

The molecular weight of chitosan isolated from Pinna deltoides discarded shells were determined using the viscometric method. A capillary viscometer from Ostwald was used to measure the viscosity of the chitosan. By measuring the sample at the suggested MarkHouwink-Kuhn-Sakurada (MHKS) equation in 0.3 molars acetic acid, 0.2 molar sodium acetate buffers, and the standard mean molecular weight (Mv) of chitosan [29], the observed intrinsic viscosity $(\eta)$ was calculated:

$$
[\eta]=\mathrm{k} \mathrm{M}_{\mathrm{v}}{ }^{\mathrm{a}}
$$

Where $\mathrm{k}$ of the polymer, solvent, and temperature-related coefficients are highly dependent [29], the $\mathrm{M}_{\mathrm{v}}$ is the mean molecular weight, as well as the $\eta$ is the intrinsic viscosity. For a $0.3 \mathrm{M}$ acetate buffer of chitosan, $0.2 \mathrm{M}$ acetate buffer of sodium $\left(25^{\circ} \mathrm{C}\right)$ is $1.38=10-5$ and $\mathrm{a}=0.85$.

\subsubsection{Micro Raman spectroscopy.}

Micro Raman spectroscopy was utilized in this work to investigate the vibrational manners of layers utilizing a Princeton instrument Acton SP 2500 (Japan) and argon laser at a wavelength of $632 \mathrm{~nm}$. 
2.1.3. X-ray powder diffractometry (XRD).

Chitosan crystallinity was determined using an X 'Pert PRO PAN (NL) $40 \mathrm{kV}$ and 30 $\mathrm{mA}$ analytical equipment with $\mathrm{Cu} \mathrm{k}=1.5406 \mathrm{~A} 0$. In a dispersion range of $4-40^{\circ}$, the relative intensity was recorded.

\subsubsection{Thermogravimetric analysis (TGA).}

Mettler Toledo TGA 2 was utilized to ascertain the change in mass of the chitosan sample. The thermal permanency of the material was tested at temperatures ranging from 0 to $600^{\circ} \mathrm{C}$.

\subsubsection{Scanning electron microscopy (SEM).}

For analysis, the sample was placed on carbon tape and then spin-coated with a gold layer. The TESCAN Oxford was used to create the Scanning Electron Micrographsand the SEM micrographs were obtained at various magnifications.

\section{Results and Discussion}

\subsection{Extraction of chitosan from Pinna deltoides.}

Pinna deltoides shells yielded an average of $70.671 .50 \%$ chitin, and a percentage yield of chitosan was $45.01 \%$ from a $100 \mathrm{~g}$ of chitin. It was discovered that the yield of chitosan in the current research is higher than yields obtained in earlier studies, such as chiton shell (4.3 $\%$, N. crepidularia (35.43\%), Metapenaeus affinis (Jinga Shrimp) (19.13\%), Penaeus monodon (Giant Tiger Prawn) (16.75\%) and Portunus pelagicus (Blue Swimmer Crab) (20.8 and $20.14 \%$ for males and females, respectively) [4,30,31].

\subsection{Characterization of chitosan.}

\subsubsection{Fourier transform infrared spectroscopy (FTIR)}

The outcomes of FTIR revealed a C-O-C glycosidic connection at $1156 \mathrm{~cm}^{-1}$, NHCO group complex vibration at $1261 \mathrm{~cm}^{-1}$, Aliphatic compound, $-\mathrm{CH}_{2}$ bend at $1418 \mathrm{~cm}^{-1}$, Amine, $\mathrm{NH}_{2}$ stretch and $\mathrm{O}-\mathrm{H}$ stretch at $3435 \mathrm{~cm}^{-1}, \mathrm{CH}_{2}$ stretching Asymmetric at $1204 \mathrm{~cm}^{-1}, \mathrm{NH}$ bending at $1075 \mathrm{~cm}^{-1}$ and ring bending at $953 \mathrm{~cm}^{-1}$. Functional groups like carbon, nitrogen, and oxygen are represented by vibration patterns determined from the FTIR spectrum (Fig. 1).

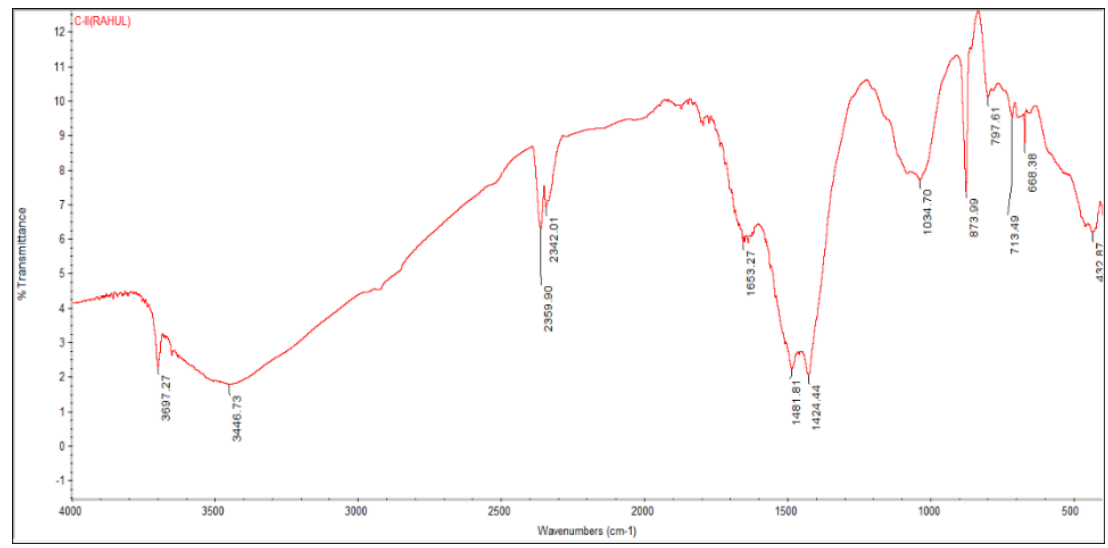

Figure 1. FTIR spectra of chitosan isolated from Pinna deltoides. 
The characterization of chitosan by FTIR showed comparable findings to those reported in previous investigations $[2,4,8,13,27,32,33]$. Chitosan from several samples contains peaks at $1029 \mathrm{~cm}^{-1}$, which relate to the unrestricted amino group at glucosamine $\mathrm{C}_{2}$ [34]. Saraswathy et al., 2001 [35] found that the major absorption band at a glucosamine $\mathrm{C}_{2}$ location in $S$. tranquebarica lies amongst 1220 and $1020 \mathrm{~cm}^{-1}$, indicating the presence of a free amino group (-NH${ }_{2}$ ). In the Mytilus edulis chitosan spectra, C-N stretching had an absorption peak at 863 $\mathrm{cm}^{-1}, \mathrm{C}-\mathrm{O}$ glucose bending had an absorption peak at 1019 and $1063 \mathrm{~cm}-1$ and C-H side-chain bending $-\mathrm{CH}_{2} \mathrm{OH}$ was supplied to those at 1421 and $1486 \mathrm{~cm}^{-1}$ [30]. Sepia pharaonic has the $\mathrm{OH}$ stretching at $3452 \mathrm{~cm}^{-1}$, as well as the $\mathrm{CO}$ (amide) and $\mathrm{NH}$ major amine bending at 1638 $\mathrm{cm}^{-1}[36]$.

The degree of deacetylation (DA) of chitosan extricated from $P$. deltoides was evaluated by utilizing the FTIR spectrum. The degree of deacetylation was high, at $55.17 \%$. The amide to hydroxyl group absorbance ratio [37] is used to determine the DA. Shrimp shells exhibited a greater DA than other chitosan outlets, with a deacetylation rate of about $77 \%$, according to prior studies. Deacetylation of Mytilus edulis (69.60 0.12\%) was greater than that of Laevicardium attenuatum (37.30 $0.31 \%$ ), with $54.65 \%$ intermediate shrimp shell deacetylation for the two exoskeletons examined and $73.6 \%$ for Aspergillus niger mycelium [38-40]. The low degree of deacetylation seen in the current work might be caused due to the deacetylation circumstances (alkali pressure, chitin tension, and no pulverization) [41,42].

The molecular weight (MW) of chitosan is determined to be $492.94 \mathrm{kDa}$, which is consistent with earlier findings [29]. Chitosan's molecular weight is a significant factor in biological applications. Because of variations in deacetylation and chitosan sources, chitosan has a wide variety of molecular weights. The molecular weight (MW) of chitosan is influenced by temperature, alkaline concentration, and reaction duration [29].

\subsubsection{Micro Raman spectroscopy.}

Micro Raman spectra of chitosan has been monitored in the scale of $1085-4100 \mathrm{~cm}^{-1}$. Peaks of $2937 \mathrm{~cm}^{-1}$ (31598 counts/s), $1106 \mathrm{~cm}^{-1}$ (27551 counts/s) and $1376 \mathrm{~cm}^{-1}$ (29116 counts/s) were predicted for chitosan (Fig. 2).

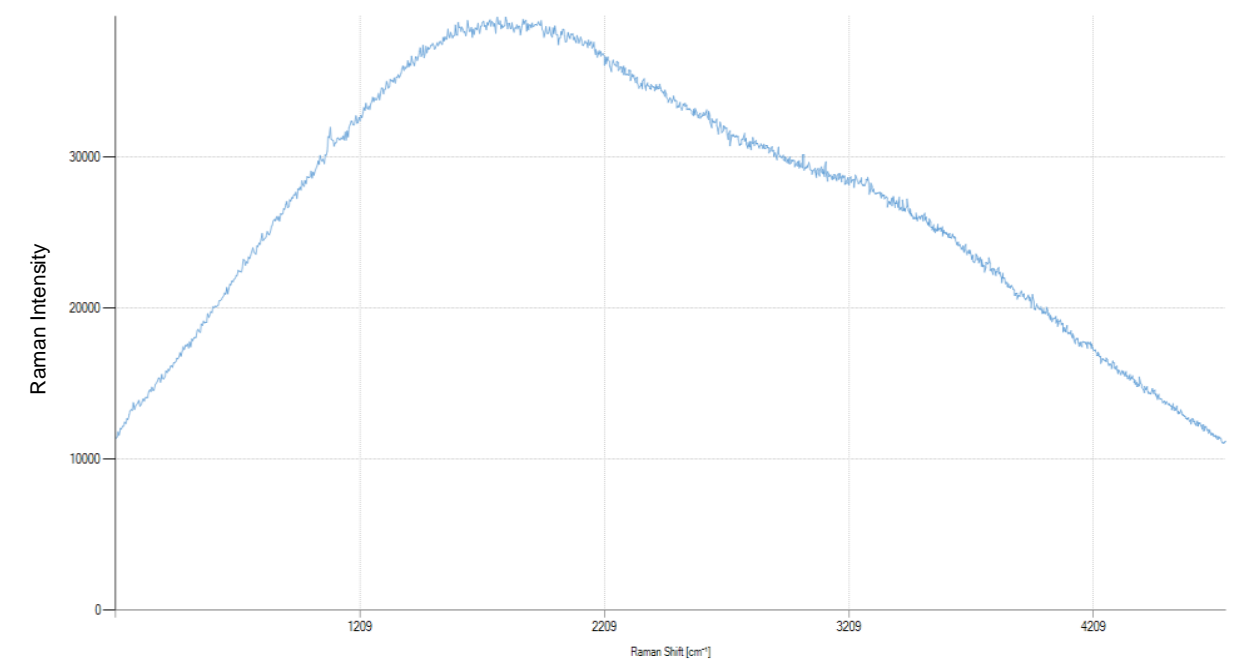

Figure 2. Micro Raman spectra of chitosan extracted from Pinna deltoides. 
The fundamental chemistry and structural orientation are determined using Raman spectroscopy. Raman spectroscopy was used to examine chitin and its derivatives. Previous research has found a linear variance in the Micro Raman spectra of chitosan at the wavelength of $2178 \mathrm{~cm}^{-1}$ with typical chitosan modifications at $1774 \mathrm{~cm}^{-1}$ and $1929 \mathrm{~cm}^{-1}$. The micro-Raman shifts were measured between 1095 and $4095 \mathrm{~cm}^{-1}$, with a maximum count of 10000 counts per second $[2,4,36]$. Chitosan's highest peak was found in the $2095 \mathrm{~cm}^{-1}$ and $3095 \mathrm{~cm}^{-1}$ ranges.

3.2.3. X-ray powder diffractometry (XRD).

XRD investigations revealed nine distinct peaks at $29.92^{\circ}, 34.59^{\circ}, 36.91^{\circ}, 41.59^{\circ}$, $44.19^{\circ}, 46.66^{\circ}, 49.14^{\circ}, 45.56^{\circ}$ and $53.76^{\circ}$. The greatest amounts of chitosan were monitored in the span of $2 \theta$ to about $20^{\circ}-25^{\circ}(1002.2$ count/s) (Fig. 3).

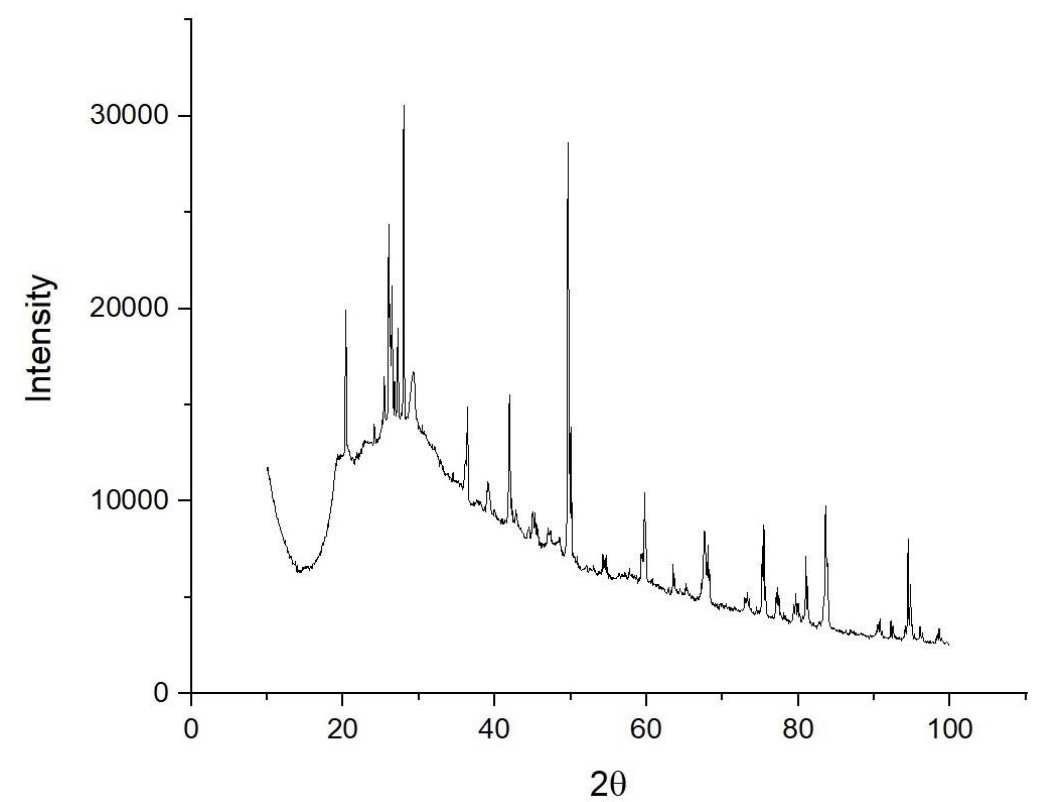

Figure 3. XRD spectra of chitosan extracted from Pinna deltoides.

Previous research [28] had shown similar results with five crisp, crystalline reflections. The denser crystalline structure is shown by, the sharper chitosan peaks of $20.92^{\circ}$ in this research [34]. At about $30-35^{\circ}$, additional chitosan reflexes were found to be virtually identical to those in the current investigation [28].

\subsubsection{Thermogravimetric analysis (TGA).}

Figure 4 depicts the thermal activity of chitosan isolated from $P$. deltoides. Thermogravimetric study of $P$. deltoides reveals three phases of mass loss. At $50^{\circ} \mathrm{C}$, the first stage of mass loss occurs, with a loss of mass of around $0.4110 \%$. At $250^{\circ} \mathrm{C}$, the second segment of weight deficiency was identified, with a percentage of mass loss of $1.5024 \%$. At $450^{\circ} \mathrm{C}$, the third mass loss stage was observed, with a percentage loss of mass of $0.8360 \%$. 


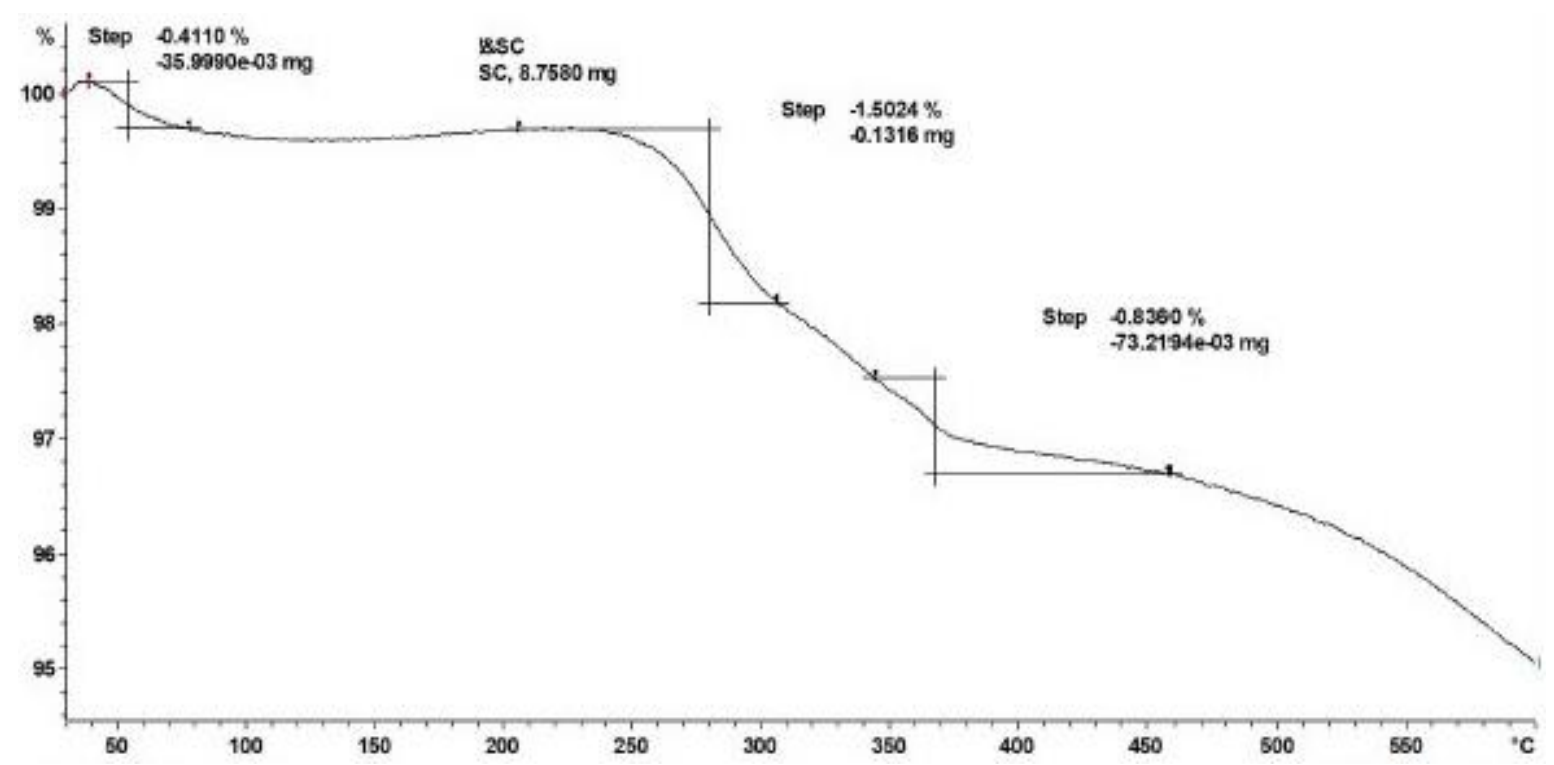

Figure 4. Thermogravimetric analysis of chitosan extracted from Pinna deltoides.

The loss of mass in the first stage is because of the vaporization of liquid content, whereas the loss of mass in the subsequent and third phases is due to polysaccharide breakdown $[43,44]$. The current research's thermal deterioration pattern matches that of a prior study $[25,32]$.

\subsubsection{Scanning electron microscopy (SEM).}

The chitosan sample was exposed to SEM analysis in order to comprehend its morphology better. Figure 5 shows electron micrographs at various magnifications of distinct sections of the chitosan isolated from $P$. deltoides. The chitosan has a porous free smooth texture, as seen by SEM micrographs, which is consistent with earlier research [45].

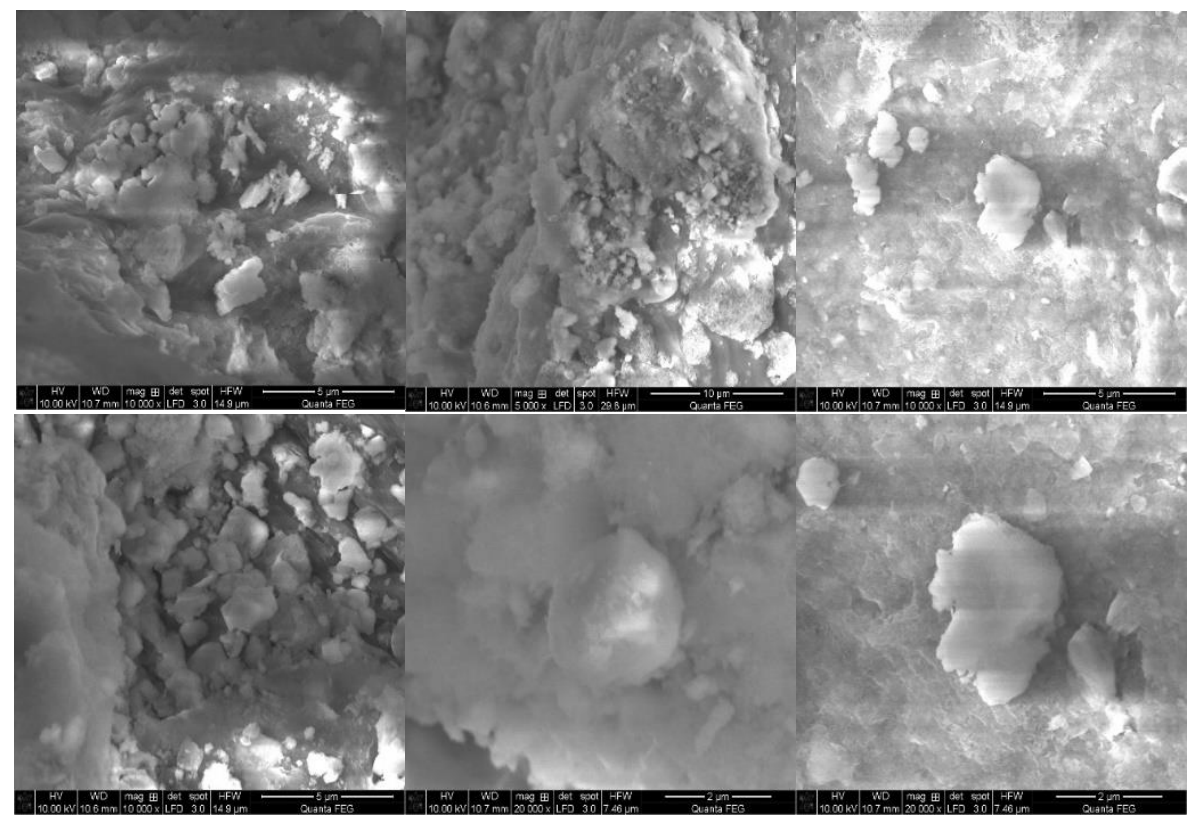

Figure 5. SEM micrographs of chitosan extracted from Pinna deltoides at different magnifications. 


\section{Conclusions}

Pinna deltoides, or pen shells, is a by-catch that is usually abandoned by fishermen. Instruments such as FTIR, Micro Raman Spectroscopy, X-ray Powder Diffractometry (XRD), TGA, and SEM were used to conduct an extensive study on the characteristics of chitosan isolated from Pinna deltoides. The present report's characterization results revealed parallels with prior research, indicating that the sample is chitosan. It is envisioned to scrutinize the antibacterial properties of chitosan derived from Pinna deltoides against different gram stains. Chitosan has also been discovered to have a lot of promise for various uses, particularly in the realm of biomedical applications.

\section{Funding}

This research did not receive any specific grant from funding agencies in the public, commercial, or not-for-profit sectors.

\section{Acknowledgments}

This article has been written with the financial support of UGC STRIDE Component -I grant sanctioned vide Letter No. F. 2-5/2019 (STRIDE-I), Dt.03.12.2019.

\section{Conflicts of Interest}

The authors declare no conflict of interest.

\section{References}

1. Shahidi, F.; Arachchi, J.K.V.; Jeon, Y.J. Food applications of chitin and chitosans. Trends Food Sci. Technol. 1999, 10, 37-51, https://doi.org/10.1016/S0924-2244(99)00017-5.

2. Sudatta, B.P.; Sugumar, V.; Varma, R.; Nigariga, P. Extraction, characterization and antimicrobial activity of chitosan from pen shell, Pinna bicolor. Int. J. Biol. Macromol. 2020, 163, 423-430, https://doi.org/10.1016/j.ijbiomac.2020.06.291.

3. Minke, R.; Blackwell, J. The structure of $\alpha$-chitin. J. Mol. Biol. 1978, 120, 167-181, https://doi.org/10.1016/0022-2836(78)90063-3.

4. Varma, R.; Vasudevan, S. Extraction, characterizationand antimicrobial activity of chitosan from horse mussel Modiolus modiolus. ACS Omega 2020, 5, 20224-20230, https://doi.org/10.1021/acsomega.0c01903.

5. Ngo, D.N.; Kim, M.M.; Kim, S.K. Chitin oligosaccharides inhibit oxidative stress in live cells. Carbohydr. Polym. 2008, 74, 228-234, https://doi.org/10.1016/j.carbpol.2008.02.005.

6. Beyazit, N.; Çakran, H.S.; Cabir, A.; Akışcan, Y.; Demetgül, C. Synthesis, characterization and antioxidant activity of chitosan Schiff base derivatives bearing (-)-gossypol. Carbohydr. Polym. 2020, 240, https://doi.org/10.1016/j.carbpol.2020.116333.

7. Moussaoui, Y.; Mnasri, N.; Elaloui, E.; Ben Salem, R.; Lagerge, S.; De Menorval, L.C. Preparation of chitosan gel. EPJ Web Conf. 2012, 29, 1-8, https://doi.org/10.1051/epjconf/20122900034.

8. Majekodunmi, S.O.; Olorunsola, E.O.; Uzoaganobi, C.C. Comparative physicochemical characterization of chitosan from shells of two bivalved mollusks from two different continents. Am. J. Polym. Sci. 2017, 7, 1522.

9. Rashki, S.; Asgarpour, K.; Tarrahimofrad, H.; Hashemipour, M.; Ebrahimi, M.S.; Fathizadeh, H.; Khorshidi, A.; Khan, H.; Marzhoseyni, Z.; Salavati-Niasari, M. Chitosan-based nanoparticles against bacterial infections. Carbohydr. Polym. 2021, 251, https://doi.org/10.1016/j.carbpol.2020.117108.

10. Agnihotri, S.A.; Mallikarjuna, N.N.; Aminabhavi, T.M. Recent advances on chitosan-based micro- and nanoparticles in drug delivery. J. Control. Release 2004, 100, 5-28, https://doi.org/10.1016/j.jconrel.2004.08.010.

11. Nagpal, K.; Singh, S.K.; Mishra, D.N. Chitosan nanoparticles: A promising system in novel drug delivery. Chem. Pharm. Bull. 2010, 58, 1423-1430, https://doi.org/10.1248/cpb.58.1423.

12. Corazzari, I.; Nisticò, R.; Turci, F.; Faga, M.G.; Franzoso, F.; Tabasso, S.; Magnacca, G. Advanced physicochemical characterization of chitosan by means of TGA coupled on-line with FTIR and GCMS: Thermal 
degradation and water adsorption capacity. Polym. Degrad. Stab. 2015, 112, 1-9, https://doi.org/10.1016/j.polymdegradstab.2014.12.006.

13. Gokula, V. Extraction and FTIR characterization of chitosan from Portunus pelagicus shell wastes. Int. J. Adv. Sci. Res. Manag. 2018, 3, https://doi.org/10.36282/ijasrm/3.10.2018.879.

14. Vijayalakshmi, V.; Hina Kousar, P.A.; Das, S. Optimization and characterization of chitosan based nanocarrier for the application of cancer drug delivery. J. Crit. Rev. 2020, 7, 762-769, https://doi.org/10.31838/jcr.07.07.139.

15. Vallapa, N.; Wiarachai, O.; Thongchul, N.; Pan, J.; Tangpasuthadol, V.; Kiatkamjornwong, S.; Hoven, V.P. Enhancing antibacterial activity of chitosan surface by heterogeneous quaternization. Carbohydr. Polym. 2011, 83, 868-875, https://doi.org/10.1016/j.carbpol.2010.08.075.

16. Yuwei, C.; Jianlong, W. Preparation and characterization of magnetic chitosan nanoparticles and its application for Cu(II) removal. Chem. Eng. J. 2011, 168, 286-292, https://doi.org/10.1016/j.cej.2011.01.006.

17. Gardiner, D.J. Introduction to Raman Scattering. In: Practical Raman Spectroscopy. 1989; https://doi.org/10.1007/978-3-642-74040-4.

18. Kumari, S.; Rath, P.K. Extraction and Characterization of Chitin and Chitosan from (Labeo rohita) Fish Scales. Procedia Mater. Sci. 2014, 6, 482-489, https://doi.org/10.1016/j.mspro.2014.07.062.

19. Hazle, M.A.; Mehicic, M.; Gardiner, D.J.; Graves, P.R. Practical Raman Spectroscopy: Springer Verlag, Berlin, 1989 (ISBN 3-540-50254-8). viii + 157 pp. Price DM 78.00. Vibrational Spectroscopy 1990, 1, 104, https://doi.org/10.1016/0924-2031\%2890\%2980015-V.

20. Haufe, S.; Bohrisch, J.; Schwarz, D.; Bratskaya, S.Y.; Steinbach, C.; Schwarz, S. Flocculation efficiency of reacetylated water soluble chitosan versus commercial chitosan. Colloids Surfaces A Physicochem. Eng. Asp. 2017, 532, 222-227, https://doi.org/10.1016/j.colsurfa.2017.05.013.

21. Szymanska-Chargot, M.; Chylinska, M.; Gdula, K.; Koziol, A.; Zdunek, A. Isolation and characterization of cellulose from different fruit and vegetable pomaces. Polymers (Basel) 2017, 9, https://doi.org/10.3390/polym9100495.

22. Szymańska-Chargot, M.; Chylińska, M.; Pertile, G.; Pieczywek, P.M.; Cieślak, K.J.; Zdunek, A.; Frąc, M. Influence of chitosan addition on the mechanical and antibacterial properties of carrot cellulose nanofibre film. Cellulose 2019, 26, 9613-9629, https://doi.org/10.1007/s10570-019-02755-9.

23. Reddy, D.H.K.; Lee, S.M. Application of magnetic chitosan composites for the removal of toxic metal and dyes from aqueous solutions. Adv. Colloid Interface Sci. 2013, 201-202, 68-93, https://doi.org/10.1016/j.cis.2013.10.002.

24. Kaya, M.; Baran, T.; Asan-Ozusaglam, M.; Cakmak, Y.S.; Tozak, K.O.; Mol, A.; Mentes, A.; Sezen, G. Extraction and characterization of chitin and chitosan with antimicrobial and antioxidant activities from cosmopolitan Orthoptera species (Insecta). Biotechnol. Bioprocess Eng. 2015, 20, 168-179, https://doi.org/10.1007/s12257-014-0391-z.

25. Riaz, A.; Lagnika, C.; Abdin, M.; Hashim, M.M.; Ahmed, W. Preparation and characterization of chitosan/gelatin-based active food packaging films containing apple peel nanoparticles. J. Polym. Environ. 2020, 28, 411-420, https://doi.org/10.1007/s10924-019-01619-4.

26. Scheltema, A. Pinna deltodes menke newly described and differentiated from P. bicolor gmelin (Bivalvia, Pterioida). J. Malacol. Soc. Aust. 1983, 6, 37-52, https://doi.org/10.1080/00852988.1983.10673953.

27. Kaya, M.; Baran, T.; Karaarslan, M. A new method for fast chitin extraction from shells of crab, crayfish and shrimp. Nat. Prod. Res. 2015, 29, 1477-1480, https://doi.org/10.1080/14786419.2015.1026341.

28. Rasti, H.; Parivar, K.; Baharara, J.; Iranshahi, M.; Namvar, F. Chitin from the mollusc chiton: Extraction, characterization and chitosan preparation. Iran. J. Pharm. Res. 2017, 16, 366-379, https://doi.org/10.22037/ijpr.2017.1963.

29. Shanmugam, A.; Subhapradha, N.; Suman, S.; Ramasamy, P.; Saravanan, R.; Shanmugam, V.; Srinivasan, A. Characterization of biopolymer "Chitosan" from the shell of donacid clam Donax scortum (Linnaeus, 1758) and its antioxidant activity. Int. J. Pharm. Pharm. Sci. 2012, 4, 460-465.

30. Palpandi, C.; Shanmugam, V.; Shanmugam, A. Extraction of chitin and chitosan from shell and operculum of mangrove gastropod Nerita (Dostia ) crepidularia Lamarck. Int. J. Med. Med. Sci. 2009, 1, 198-205.

31. Sagheer, F.A.A.; Al-Sughayer, M.A.; Muslim, S.; Elsabee, M.Z. Extraction and characterization of chitin and chitosan from marine sources in Arabian Gulf. Carbohydr. Polym. 2009, 77, 410-419, https://doi.org/10.1016/j.carbpol.2009.01.032.

32. Ahyat, N.M.; Mohamad, F.; Ahmad, A.; Azmi, A.A. Chitin and chitosan extraction from Portunus pelagicus. Malaysian J. Anal. Sci. 2017, 21, 770-777, https://doi.org/10.17576/mjas-2017-2104-02.

33. Lavall, R.L.; Assis, O.B.G.; Campana-Filho, S.P. $\beta$-Chitin from the pens of Loligo sp.: Extraction and characterization. Bioresour. Technol. 2007, 98, 2465-2472, https://doi.org/10.1016/j.biortech.2006.09.002.

34. Divya, K.; Rebello, S.; Jisha, M.S. A simple and effective method for extraction of high purity chitosan from shrimp shell waste. Int. Conf. Adv. Appl. Sci. Environ. Eng. 2014, 141-145.

35. Saraswathy, G.; Pal, S.; Rose, C.; Sastry, T.P. A novel bio-inorganic bone implant containing deglued bone, chitosan and gelatin. Bull. Mater. Sci. 2001, 24, 415-420, https://doi.org/10.1007/BF02708641. 
36. Karthik, R.; Manigandan, V.; Saravanan, R.; Rajesh, R.P.; Chandrika, B. Structural characterization and in vitro biomedical activities of sulfated chitosan from Sepia pharaonis. Int. J. Biol. Macromol. 2016, 84, 319328, https://doi.org/10.1016/j.ijbiomac.2015.12.030.

37. Hussain, R.; Maji, T.K.; Maji, T.K. Determination of degree of deacetylation of chitosan and their effect on the release behavior of essential oil from chitosan and chitosan-gelatin complex microcapsules. Int. J. Adv. Eng. Appl. 2013, 2, 4-12.

38. Muñoz, G.; Valencia, C.; Valderruten, N.; Ruiz-Durántez, E.; Zuluaga, F. Extraction of chitosan from Aspergillus niger mycelium and synthesis of hydrogels for controlled release of betahistine. React. Funct. Polym. 2015, 91-92, 1-10, https://doi.org/10.1016/j.reactfunctpolym.2015.03.008.

39. Al-Hassan, A.A. Utilization of waste: Extraction and characterization of chitosan from shrimp byproducts. Civ. Environ. Res. 2016, 8, 2224-5790.

40. Negm, N.A.; Hefni, H.H.H.; Abd-Elaal, A.A.A.; Badr, E.A.; Abou Kana, M.T.H. Advancement on modification of chitosan biopolymer and its potential applications. Int. J. Biol. Macromol. 2020, 152, 681702, https://doi.org/10.1016/j.ijbiomac.2020.02.196.

41. Hossain, M.S.; Iqbal, A. Production and characterization of chitosan from shrimp waste. J. Bangladesh Agril. Univ 2014, 12, 153-160, http://dx.doi.org/10.3329/jbau.v12i1.21405.

42. Renata, C.-B.; Diana, J.; Bozena, R.; Piotr, U.; Janusz, M.R. Determination of degree of deacetylation of chitosan - Comparision of methods. Prog. Chem. Appl. Chitin its Deriv. 2012, 17, 5-20.

43. Savin, C.L.; Popa, M.; Delaite, C.; Costuleanu, M.; Costin, D.; Peptu, C.A. Chitosan grafted-poly(ethylene glycol) methacrylate nanoparticles as carrier for controlled release of bevacizumab. Mater. Sci. Eng. C 2019, 98, 843-860, https://doi.org/10.1016/j.msec.2019.01.036.

44. Kaya, M.; Baran, T.; Mentes, A.; Asaroglu, M.; Sezen, G.; Tozak, K.O. Extraction and characterization of $\alpha-$ chitin and chitosan from six different aquatic invertebrates. Food Biophys. 2014, 9, 145-157, https://doi.org/10.1007/s11483-013-9327-y.

45. Eddya, M.; Tbib, B.; EL-Hami, K. A comparison of chitosan properties after extraction from shrimp shells by diluted and concentrated acids. Heliyon 2020, 6, https://doi.org/10.1016/j.heliyon.2020.e03486. 